\title{
A contemporary and innovative care model for older adults
}

Renato Veras' ${ }^{\prime}$

\section{Abstract}

The population aging that has arisen from Brazil's new demographic and epidemiological reality, a relatively recent phenomenon, requires innovative and efficient responses. This article presents a care model for the older population with the most contemporary comprehensive care and an excellent cost-benefit ratio. The proposal is aimed at health promotion, disease prevention and the coordination of care, with an emphasis on low complexity instances of care. The integrated models seek to solve the problem of fragmented and poorly coordinated care in current health systems. For this reason, we propose a low complexity care unit, an epidemiological assessment, a social center and a team formed by a pair of medical and nursing professionals, with the support of gerontologists. There will also be medical records that cover clinical and social aspects, as well as a quality information system - all involving advanced technology, accessible by doctors and clients at any time via cloud technology and a cell phone app. The more the healthcare professional knows their patient's history, the better the results. The concepts and structure that underlie this model, which aims to reduce waste, offering greater quality at reduced cost, are set out. It is our contribution to benefit - be it in the public or supplementary sector - health care aimed at the fastest growing age group in Brazil.
Keywords: Aging. Disease Prevention. Care Coordination. Technology and Information.

Performance Payment.

Universidade Aberta da Terceira Idade (UnATI - UERJ), Rio de Janeiro, Brasil.

No funding was received in relation to the present study.

The author declares that there is no conflict of interest involved in this work.

Correspondence 


\section{INTRODUCTION}

One of humanity's greatest achievements has been the growth of life expectancy. Reaching old age - once the privilege of a few - has become the norm in even the poorest countries, and has been accompanied by a substantial improvement in populational health parameters, although the distribution of these achievements across different countries and socioeconomic contexts has been far from equal. The challenge, therefore, is to add quality to these additional years of life ${ }^{1}$.

The demographic transition and improvement in social and economic indicators in Brazil, in comparison with previous decades, has brought an increase in the older population and greater financial pressure on public and private health systems. If this sector of the population increases, so chronic diseases and costs will grow ${ }^{1}$. One result is a growing demand for health services, which at the same time, can generate shortages or restrictions in medical resources. The diseases that affect older adults are mainly chronic and multiple, requiring constant monitoring and permanent care ${ }^{2}$. They involve an excess of appointments by specialists, more frequent hospitalizations, and longer bed occupancies than other age groups ${ }^{3}$.

The current provision of health services fragments care for this age group, with a multiplication of specialist consultations, a lack of information sharing, and the use of countless drugs, clinical and imaging exams, among other procedures that burden the system, causing a serious financial impact at all levels, and which fail to generate significant benefits for health or quality of life $^{3}$. A great burden caused by disease can be avoided, in both social and economic terms.

In their book Rethinking Health: strategies to improve quality and reduce costs, M. Porter and E. Teisberg argue that health precedes care. According to the authors, there is a latent need to measure and minimize the risk of illness, offer comprehensive disease management and guarantee prevention services for all older adults, including healthy individuals. They argue that health must include a prepared health service (increasing the efficiency of the value chain), intervention, recovery, the monitoring and management of the clinical condition of the patient, the guarantee of access, the measuring of results and, finally, the dissemination of information ${ }^{4}$.

There are still disagreements about the ideal percentage to be invested in health promotion, when compared to the volume allocated to care. While it is a complex and flexible calculation, one thing is certain: investment must be increased to prevent people from becoming $\mathrm{ill}^{4}$. Prevention is not a cost, but an investment with a guaranteed profit, provided it is done effectively. By encouraging prevention and delaying the occurrence of illnesses, we help to preserve the so-called "functional capacity". With the rapid and intense aging of the Brazilian population, this has become the new paradigm and the main strategic indicator in health.

\section{AGING AND HEALTH}

Health is defined as the measure of an individual's ability to fulfill their aspirations and meet their needs, regardless of age or the presence of diseases ${ }^{5}$. Thus, an efficient and complete geriatric assessment, at reasonable cost, is ever more urgent. Its objectives are the early diagnosis of diseases and the guidance of support services where necessary, in order to avoid hospitalizations. A medical history, physical examination and individual diagnosis are not sufficient for an extensive survey of the various functions required in the daily life of an older adult ${ }^{6}$.

Well-being and functionality are complementary. They represent the presence of autonomy - the individual capacity to make decisions and have command over actions, establishing and following one's own convictions - and independence - the ability to accomplish something through one's own means - allowing the individual to take care of themselves and their life ${ }^{5}$. Although independence and autonomy are closely related, they are different concepts. There are those who are physically dependent, but who can decide on the activities that interest them. In contrast, there are those who have the physical capacity to perform certain daily tasks, but who are unable to safely decide how, when and where to perform them ${ }^{5}$. 
Determining the health conditions of the older population must consider overall health status, that is, it should take into account a satisfactory level of functional independence, and not just the absence of disease. Thus, the idea of functionality is considered to be a paradigm of the health of older adults, and becomes one of the most important attributes of human aging, as it deals with the interaction between the physical and psycho-cognitive capacity for carrying out activities of daily living ${ }^{5}$.

Monitoring the health conditions of a given population, as well as its associated factors, is a key tool for guiding prevention strategies, which should aim to: positively influence the natural history of the disease, anticipate the onset of complications, prevent exacerbations and complications of chronic illnesses, increase patient involvement in self-care and build a database of chronic patients (mostly older adults).It is possible to prevent most public health problems affecting the population - not only those related to communicable diseases, but also to noncommunicable illnesses. This finding is evidenced by the significant decrease in mortality from coronary and cerebrovascular diseases, the reduction in the incidence of and mortality from cervical cancer, as well as a reduction in the prevalence of smoking and the incidence of lung cancer in men $^{7}$.

Chronic diseases have one or more of the following characteristics ${ }^{8}$ : they are permanent, result in disability or deficiencies, are caused by irreversible pathological changes and require long periods of supervision, observation or care. In general, they start slowly, and have no single cause. Treatment involves lifestyle changes and continuous care that does not usually lead to a cure, but allows the disease to be controlled and the quality of life of the patient to improve, in order to prevent or mitigate functional decline $^{5}$. Most chronic diseases are related to age, poor eating habits, physical inactivity and stress, so most can be prevented and/or delayed. This means that, despite the disease, it is possible to live a fuller life for longer?

A contemporary healthcare model for older adults should be built around a flux of educational and health promotion actions, the prevention of preventable diseases and the delay, early treatment and rehabilitation of illnesses. In other words, a line of care - strategies for establishing the care path, with the objective of organizing the flow of individuals according to their needs - for older adults that hopes to achieve efficacy and efficiency must presuppose an interconnected network, based on the integrality of care, with the reference health professional and their team managing the individual instead of the disease, using all available technologies, based on the information obtained from quality medical records and frequent monitoring ${ }^{8}$.

It is not logical to make hospitals the gateway to this health system, when the most contemporary medical thinking shows that this level of care, in addition to being more expensive, should be restricted to specific recommendations. Homecare is a more contemporary modality. In fact, the "invention" of the modern hospital is itself recent. Until quite recently, care was provided in the home ${ }^{10}$.

One example is the prospective evaluation of the disease management ${ }^{10}$ offered to beneficiaries of Medicare (the US government-run health insurance system), which demonstrated that actions failed to reduce expenses and that doctors resented the decision of the insurance companies to pay the costs of disease management, possibly reducing their earnings and interfering with the doctor-patient relationship.

Disease management programs for older adults, which are more complex, have a low cost-benefit ratio, as treating a disease reduces only morbidity rates. As older patients are affected by several chronic diseases, prioritizing a single disease over others is not the best choice of action. The best alternative is to structure integrated models that care for all the needs of these patients. If not, the problem is unlikely to be solved, as other diseases and their frailty will be maintained. In addition, resources will be used improperly ${ }^{10}$.

\section{THE PROPOSED MODEL}

This model is structured around a treatment system that favors integrated care and prevention through the continuous monitoring of health conditions and the coordination of care at all levels. In this way, it is possible to stabilize chronic diseases 
and avoid overburdening the system ${ }^{10,11}$. The training and knowledge of healthcare professionals involved in the model must be continually refreshed, to ensure they are as qualified as possible. Geriatricians must have fundamental training in Family and Community Medicine, focusing on the provision of primary care. In this way, a service focused on the needs of each beneficiary is guaranteed, recognizing clients as the subject of the process, and through effective communication with their families, respecting their interactions.

An important space in health units is the social center, which plays an essential role as a place for the integration of various health education, promotion and prevention actions.

Functional assessment determines the allocation of older patients into the correct line of care, in addition to allowing their care behaviors to be anticipated. There are a series of assessment tools for risk tracking validated and translated into Portuguese. Functional autonomy is an important predictor of the health of older patients, but systematically assessing the entire older population using long and comprehensive scales is not ideal. The two-phase approach, concentrating the complete assessment only on older people at risk, identified by a screening process, is more effective and less costly.

For this first contact, we opted for the tool known as Prisma-7, a questionnaire developed in Canada and composed of seven items. Its cross-cultural validation and adaptation for Brazil indicated a score of four or more positive responses as the ideal cutoff point. The application of the instrument, which can be carried out in three minutes, does not require expensive technology, personnel with special qualifications or long training programs. The respondents' sociocultural and educational levels do not influence the understanding of the questions and if necessary, the questionnaire can be self-administered ${ }^{11}$. Prisma-7 has been used as a screening tool for functional loss and frailty at the entry point to Canada's healthcare system, as well as by the British Geriatrics Society and the Royal College of General Practitioners, in England $^{12,13}$. In this proposal, some of the main protocols previously translated and validated in Brazil will be used.

\section{INTERDISCIPLINARY TEAM}

The proposed program is based on a partnership comprising a geriatrician doctor and a gerontologist nurse. The doctor performs clinical management, while the nurse coordinates care, monitoring the health conditions of users and consolidating the reference role of the model through client intake and strengthening the bond with patients.

The team is also composed of physiotherapy, psychology, social care and nutrition professionals, in addition to workshop staff (who develop dynamic integrative activities linked to the program). Whenever the care needs of users require other levels of care, they can be referred, but always by the client's doctor (geriatrician, general practitioner or family doctor). The same procedure is used for hospitalization. The doctor and nurse are responsible for contacting the hospital physicians, in order to obtain information about the case and, preferably, acting to ensure the best care and the shortest hospital stay.

The model has a care manager, a nursing professional with a specialization in gerontology who accompanies the older adult and their family throughout the process. This professional is responsible for the transition of care between services and annually - or when required - assesses the individual's functional capacity, encouraging their participation in the process. Its role is extremely important for the proposed model and follows the same logic as the North American navigator, created to guide the most frail patients. It is also the responsibility of this professional to manage the user's care through the different complexity levels of the health system, checking if the prescriptions and guidelines are being fulfilled ${ }^{15}$. This is not always possible, but it is important to emphasize that keeping patients in the initial levels of the model does not mean preventing their progression to higher complexity instances of care. An example is the hospital, which should be used as an exception, rather than the rule, and for as short a time as possible. To this end, the strategy of integrated care and intense monitoring is organized, as the differentiation between low and high complexity levels of care is marked. 
In addition to the interdisciplinary team that provides face-to-face care, the model has a team of doctors and nurses working in virtual mode through the GerontoLine, a direct telephone line that guarantees full-time care, either passively (assisting and guiding) or actively (making contact to keep the individual on the care radar).

The quality of care demands greater awareness from health managers and society. It is argued that applying instruments to provide more qualified care and increased accreditation and certification is expensive, but good services are more costeffective, involve less waste and provide better care results for patients. In some countries, the accreditation and evaluation of quality indicators are mandatory requirements. In Brazil, however, a policy of encouraging quality is lacking as both public and private health systems consider it an additional cost.

Although these assumptions are accepted by most health managers, little is ever done. For this reason, for a properly structured care model, ${ }^{16}$ some elements cannot be overlooked. Briefly and concisely, the items considered essential for a contemporary and innovative health care model ${ }^{17,18}$ are presented in Chart 1, below:

Chart 1. Key items for a contemporary and innovative health care model. Rio de Janeiro, 2018.

\begin{tabular}{|c|c|}
\hline Competency & $\begin{array}{l}\text { Professionals trained to the specifics related to aging, with postgraduate degrees in } \\
\text { Geriatrics/Gerontology and regular training. }\end{array}$ \\
\hline Diagnostic reliability & Obtained through second opinions from qualified professionals. \\
\hline Qualified information & $\begin{array}{l}\text { The medical records must be designed to cover all the items described, feature the } \\
\text { latest technology and be accessible via cell phone. }\end{array}$ \\
\hline Portability & The patient is the owner of information about their health. \\
\hline Compensation and bonuses & $\begin{array}{l}\text { Health professionals should receive a financial incentive (extra remuneration) related } \\
\text { to their performance, while beneficiaries who adhere to the service should receive } \\
\text { discounts on their monthly fees. } \\
\text { Bonus - operators can offer beneficiaries who adhere to this care product a bonus, } \\
\text { that is, as the operator believes that the model is efficient and reduces costs, it can } \\
\text { and should encourage the participation of beneficiaries by granting a bonus. This is a } \\
\text { discount on the health plan monthly fee, in accordance with article 4, paragraph 1, of } \\
\mathrm{RN} \mathrm{n}^{\circ} 265 \text {, dated August 19, } 2011 \text {. } \\
\text { Remuneration - the awarding of extra remuneration for the service provider pairing } \\
\text { (doctor and nurse) who look after a client portfolio is a form of encouragement for } \\
\text { these professionals to meet the goals and results prepared in accordance with results in } \\
\text { health. It works as a stimulus and reward for those who provide higher quality care to } \\
\text { their clients, and who indirectly contribute to the reduction of the operator's costs. }\end{array}$ \\
\hline Prevention & $\begin{array}{l}\text { Monitor health, not disease; intervene before the injury or illness occurs; postpone the } \\
\text { disease so that the older adults can enjoy their quality of life for longer. }\end{array}$ \\
\hline Integrated processes & Working processes designed to avoid waste and maximize resources. \\
\hline Technology & Modern and innovative resources ensure an easy, efficient information flow. \\
\hline Transdisciplinarity & $\begin{array}{l}\text { Diverse technical knowledge, acting in an integrated way, considering the patient as a } \\
\text { whole. }\end{array}$ \\
\hline
\end{tabular}

Source: the author. 


\section{CRITERIA FOR PARTICIPATION IN THE MODEL}

For inclusion in the program, the individual must be 60 years or older. The number of comorbidities is not used as an inclusion or exclusion factor. After admission, the interested parties are seen by a nurse, who will be their monitoring manager. Initially, this professional will explain the objectives of the program, before carrying out a Comprehensive Geriatric Assessment (CGA), establishing the monitoring protocol based on the risk identified following the assessment (robust, at risk of frailty or frail). The patient is then referred for medical evaluation by the professional who will be their reference for health monitoring.

For robust patients, medical consultations are held every six months. Those at risk of frailty or who are already frail consult with their attending physician every three months. The follow-up manager performs monthly telephone monitoring, as well as arranging periodic nursing consultations and urgent emergency visits, according to the client's needs. In situations where there is a need for multidisciplinary follow-up, the nurse or the medical team refers the older patient to the social center, a facility with a fundamental role in the system as a location where various integrated actions necessary for maintaining functional capacity are carried out.

The unique electronic medical record organizes the health information of the client, allowing the planning of individual and collective action strategies focused on prevention. Computerization and the integration of management systems contribute to more effective financial control, ensuring programmed receipts are not charged, allowing analysis of data and those registered and acting as a tool for preventive actions.

A structured care program for older patients does not only benefit the quality of life of the patients monitored; it allows the health care provider to better manage the use of its financial resources.

\section{INTAKE}

The older adults and their family must feel protected and supported when entering the health system. Intake is fundamental for those joining the program and a stimulus for the development of trust.

Intake takes place in two stages. The first is administrative and institutional in nature. Ample explanation of the proposed actions is provided, emphasizing health promotion and disease prevention above all. The user is didactically informed about all the differentiated care dynamics that will be offered to improve their health and quality of life. In the second stage, the service itself begins.

As a way of organizing access to the levels of the model, the Prisma-7 risk identification questionnaire is applied. The patient then undergoes evaluation through the other instruments that make up this functional assessment ${ }^{14,19-21}$ : the Lachs Scale, the Katz Scale, the Lawton Scale, Mini Nutritional Assessment, Tinetti Scale, the Jaeguer Chart, the Mini-Mental State Examination and the Yesavage Scale, detailed in Chart 2.

In addition to risk identification and screening protocols, the other epidemiological instruments are used annually. Physician and monitoring manager, in addition to the geriatric interprofessional team, carry out more detailed assessments in order to propose an intervention plan. This information will appear in the patient's medical record and will be kept until the end of the care journey ${ }^{12}$. An individual therapeutic plan is then defined with periodic consultations, referral to a multidisciplinary team and a social center - and, if applicable, evaluation by medical specialists. A single, longitudinal and multiprofessional electronic medical record is then opened, where information from all instances of care in the care model will be stored, from the first contact to palliative care in the final phase of life. This chart should contain information about the clinical history and physical exams of the older patient, but it is essential that you have information about your daily life, your family and your social support, among others. Your medical record should also have the records of other professionals of the interdisciplinary team, such as physiotherapists, nutritionists and psychologists. Family participation, explanation of activities and epidemiological screenings resulting from assistance in the services offered are other important differentials. Information on all procedures is essential for monitoring older adults. 
Chart 2. Instruments used in the functional assessment of older adults. Rio de Janeiro, 2018.

\begin{tabular}{|l|l|}
\hline Lachs Scale & $\begin{array}{l}\text { Composed of } 11 \text { items (questions, anthropometric measurements and } \\
\text { performance tests) to assess the areas most commonly affected in older adults } \\
\text { (vision, hearing, upper and lower limbs, urinary continence, nutrition, cognition } \\
\text { and affect, activities of daily living, environment and social support). The } \\
\text { application of this instrument makes it possible, quickly and systematically, to } \\
\text { identify the functional domains that will later be evaluated in more detail for the } \\
\text { establishment of diagnosis and planning of interventions. }\end{array}$ \\
\hline Katz Scale & Evaluates self-care activities in daily life \\
\hline Lawton scale & Evaluates instrumental activities of daily living \\
\hline Mini Nutritional Assessment & Nutritional assessment \\
\hline Tinetti scale & Balance and gait test \\
\hline Jaeguer Card & Evaluates visual acuity \\
\hline Mini-Mental State Examination & Folstein test \\
\hline Yesavage scale & Geriatric depression scale \\
\hline
\end{tabular}

Source: the author

\section{CARE COORDINATION}

There are several models of lines of care, but what is most important is that each health institution understands its client portfolio, profile and needs, and organizes its services as effectively as possible $e^{11,16}$.

One of the main factors for controlling the costs of users of the program is monitoring in all instances of care, so that there is no gap in the patient's care when they are referred to the healthcare network or need tertiary or hospital care ${ }^{22}$. The transition between the instances of care is monitored by the team, which values the fluidity of the flow of information, bringing together the healthcare professionals and seeking to preserve the principles of the predominant guidance of the geriatrician and nurse pairing. The control of hospitalizations takes place through a determined flow, ensuring that those responsible for care know the clinical and treatment history of the patient, in addition to the understanding that they receive frequent monitoring and should return to their health team when the period of clinical aggravation is over ${ }^{23}$.

In the case of hospitalization, the patient is monitored on a daily basis, in two forms. In one the nurse maintains contact with the family to provide support, clarification or identify needs (of the patient or the family itself). The other involves the prevention manager, who acts as a link between outpatient clinic and hospital, carrying out daily monitoring with the attending hospital doctor. In hospitals where there is an internist, this contact is facilitated and direct. In the others, there is support from the medical auditors or the care team.

The entry point to the health system cannot be the hospital. A model should be designed with several instances of prior care. Seeing the hospital as a privileged place for healing is a conceptual error. In the case of older adults, hospitalization should occur only at the acute stage of the chronic disease and for the shortest possible time, or in cases of emergency ${ }^{11,16}$. Equally important is the emphasis that older adults participate in the activities of the social center, a place for the integration and reinforcement of integrated care policies. Research has shown a positive effect in reducing referral to specialist doctors ${ }^{3,10,11}$. Furthermore, the professionals who organize the activities are identified as team members, giving them credibility. Social centers promote meetings and interactions mediated by pedagogical plans aimed at older adults, such as health workshops, therapeutic groups, yoga, ballroom dancing, cognitive stimulation, psychology groups, nutrition, singing, postural guidance, pelvic and muscle strengthening. The objective is to reduce the problems of loneliness for older adults, improve their social contact and develop new skills at an older 
age, making it a stimulating space for exchanging experiences, mediated by a pedagogical body.

\section{TECHNOLOGY AS A DIFFERENTIATING FACTOR}

Upon arriving at the health center, the client is identified through facial recognition, which instantly opens their medical records on the receptionist's desk. When greeting the client, the receptionist can now address them by name, ask about their family and check the list of medications that the older person is taking. These are simple actions, but they add enormous trust to the relationship, making older adults feel protected and welcomed from the outset.

Registering patient care paths is another major differentiating factor. A high quality information system that is broad in scope can document not only the clinical evolution of the older person, but also their participation in individual or collective prevention actions, and provide the support of nursing professionals and telephone contacts, which must be resolutive, carried out by qualified personnel and involve complete sharing of information with the team, for the benefit of a comprehensive assessment of the individual.

The information system, which begins with the registration of the client, is one of the pillars of the program. Through the process, the entire care pathway will be monitored at every level, verifying the effectiveness of actions and contributing to decision making and monitoring. It is a single, longitudinal and multi-professional electronic record, which will accompany the patient from intake onwards, and which differs from existing records in that it records their life history and health events.

Another efficient differentiating factor is the availability of a mobile phone app with individualized information and reminders of appointments and prescribed actions. The app may, among other actions, request that the client takes a photo of their breakfast and sends it to the nutritionist, who will observe if the food is balanced, or contains adequate quantities of fiber, etc. Every effort will be made to keep users within the units of the program, with the minimum use of specialists.

\section{ACTIONS AND METRICS}

The duties of the geriatrician are: to manage the health history of their client portfolio, establishing individualized care plans; define the clinical risk of each patient and manage their care demands, together with the nurse; monitor hospitalizations; assess and process referrals to specialists; and coordinate the discussion of the most relevant clinical cases, in order to keep the team integrated and aligned with the most suitable conduct for each case.

Considering a workload of 20 hours per week, each doctor will have four shifts of five hours per week. Each shift will have slots for 12 patients, with 20 minutes per consultation, in addition to three "wildcard" slots (60 minutes) to be used for extra tasks, such as inter-consultations with the nurse, case reviews or contact with hospitalized patients. Thus, each month, the doctor will have performed an average of 200 consultations, which allows the entire user portfolio to be consulted every quarter.

\section{NURSING ACTIONS AND MEASURES}

The nurse will be responsible for four distinct and integrated actions throughout the process.

Brief functional assessment - the patient's first consultation, in which screening tests are applied and the clinical history is obtained.

Nursing consultation - the frequency of nursing consultations will be established according to the degree of frailty, classified as follows: Risk 1 - every four months; Risk 2 - every three months; and Risk 3 - every two months.

During consultations, the nurse must: monitor the most complex cases; assess compliance with the proposed targets; reestablish new goals when necessary and track possible medical needs; engage with clients to develop an individualized care plan that distinguishes their needs and meets their priorities; and ensure that beneficiaries and their families understand their role in promoting care and feel safe to carry out their joint responsibilities. 
Concomitantly, the nurse can: identify the psychological, social, financial and environmental barriers that affect the beneficiary's ability to adhere to treatments or health promotion, establishing a strategy that resolves or minimizes the problem; and oversee collective care, known as therapeutic groups, which bring together patients with the same comorbidity, in order to provide a dynamic of information and awareness of healthy practices.

Brief nursing care (BNC) - this is an ad-hoc service, performed in person and when required, in which the nurse, in a special role and without prior appointment, treats patients who, via GerontoLine, request face-to-face assistance. Considering that most complications presented by telephone or via the call-center will be managed virtually or referred to an emergency service, the time set aside in the professional's schedule for this action represents $10 \%$ of each work shift.

Monitoring - its main objective is to keep the patient in the radar of the pairing responsible for managing their health. Depending on the degree of frailty, the older adult will receive more frequent contact. The entire portfolio will be monitored at least once a month. Contacts will be via telephone or the app and will follow a structured protocol to ensure the effectiveness of the approach and the updating of the beneficiaries' health information and electronic data history. The health service professionals will be available to users 24 hours a day via virtual care.

\section{PERFORMANCE BASED REMUNERATION}

The hegemonic model of remuneration for health services in many countries, both in public systems and in those oriented to the private health plan market, is still that of fee-for-service, which remunerates the quantity of services produced (volume) and encourages competition for users.

Changing the remuneration model without changing the care model, or vice versa, is not enough, considering that both are interdependent. Some of the problems of the Brazilian health system, especially the supplementary system, and which primarily affect older adults, are a consequence of the model adopted decades ago. To cope with the new and urgent demands of society, alternative remuneration models must be implemented to break the vicious circle of a succession of fragmented consultations, decontextualized from the social and health reality of older adults, in addition to the production of procedures disconnected from the expected outcome ${ }^{24}$.

Performance based pay is a reward system based on the results obtained. As the technical and behavioral requirements required of professionals are of a high standard, it is therefore intended that the remuneration is of equivalent value.

Performance based pay, for example, establishes bonus levels that can reach 30\% in compensation in the quarter. Every three months, an assessment of the health professional's performance is made based on predetermined indicators. Considering that there is a need for four medical consultations/year as a premise of the program, one consultation per quarter is required for all clients linked to doctors. In other words: everyone will be seen by their doctor four times a year.

The prerequisites of the award are attendance and punctuality, which are fundamental to guaranteeing the number of consultations, which is an essential factor for ensuring the quality of the service. There is also a requirement to participate in the scoring program for the payment of the bonus: the proper registering of information in the electronic medical records of the participants, as well as their potential hospitalizations. As these are the main cost factor, strict control by the team determines the economic and financial success of any initiative or project.

Another basic principle is the resolutive capacity of the geriatrician. According to international studies, ${ }^{25}$ general practitioners can resolve $85 \%$ to $95 \%$ of clinical situations. Referrals to specialist clinics should be an exception. If the doctor refers up to $15 \%$ of clients in their portfolio per quarter, a good resolutive capacity, worthy of additional points, will have been demonstrated.

The engagement between users of the program and the multidisciplinary team and social center determines the client's bond and resolvability. An item is therefore included that assesses the participation 
of members of each portfolio in consultations with the gerontologists of the team and in the collective activities of the social center, which earns points towards a bonus ${ }^{26}$.

The loss ratio is the main economic and financial indicator established for the evaluation of the program, which is why this item is given greater weight, and doctors can earn up to two points in their performance evaluation. This assessment requires excellence of care, and the incentive for health professionals within the win-win premise is fair.

\section{Bonus point scoring}

The items in the portfolio of each doctor, evaluated quarterly, are shown in Table 3.

Chart 3. Items from each doctor's portfolio, evaluated quarterly. Rio de Janeiro, 2018.

\begin{tabular}{|c|c|}
\hline Percentage of clients seen & $\begin{array}{l}\text { a. } 100 \% \text { of portfolio seen in quarter ( } 1 \text { point). } \\
\text { b. From } 90 \% \text { to } 99 \% \text { seen (no points). } \\
\text { c. Below } 90 \% \text { seen (minus } 1 \text { point). }\end{array}$ \\
\hline Client Satisfaction Survey & over $90 \%=1$ point \\
\hline Doctor's resolutive capacity & $\begin{array}{l}\text { a. Use of healthcare network for less than } 15 \% \text { of cases ( } 1 \text { point). } \\
\text { b. Use of healthcare network from } 80 \% \text { to } 85 \% \text { of cases (no points). } \\
\text { c. Use of healthcare network in } 80 \% \text { of cases (minus } 1 \text { point). }\end{array}$ \\
\hline $\begin{array}{l}\text { Participation in the activities of the social } \\
\text { center, workshops or multidisciplinary } \\
\text { team. }\end{array}$ & $\begin{array}{l}\text { a. Over } 20 \% \text { of clients ( } 1 \text { point). } \\
\text { b. } 10 \text { to } 19 \% \text { (no score). } \\
\text { c. Below } 10 \% \text { (minus } 1 \text { point). }\end{array}$ \\
\hline Portfolio loss ratio & $\begin{array}{l}\text { a. Below } 70 \% \text { ( } 2 \text { points). } \\
\text { b. From } 70 \% \text { to } 79 \% \text { ( } 1 \text { point). } \\
\text { c. } 10 \text { to } 19 \% \text { (no score). } \\
\text { d. } 100 \% \text { (minus } 1 \text { point). }\end{array}$ \\
\hline
\end{tabular}

Source: the author.

There is no doubt that performance based pay models will become a reality in Brazil. Healthcare professionals must realize that the implementation of performance-based pay is not a question of when or if, but how ${ }^{12,17}$.

\section{LOSS RATIO}

The loss ration calculated from the relationship between the costs arising from losses and the premium, which corresponds to the revenue received by the health plan operator. In this way, a percentage is calculated from the amount spent divided by how much is earned.

According to the National Supplementary Health Agency (or ANS), the loss ratio is defined as the ratio, expressed as a percentage, between the health care expenses and the revenue of the operators. In a health care provider following this care model, ${ }^{12,17}$ their loss ratio data for the period from June 2014 to July 2018 were analyzed. The average age of the population participating in this program in 2019 was 71 years, and the loss ratio over time is shown in figure 1 , below. 


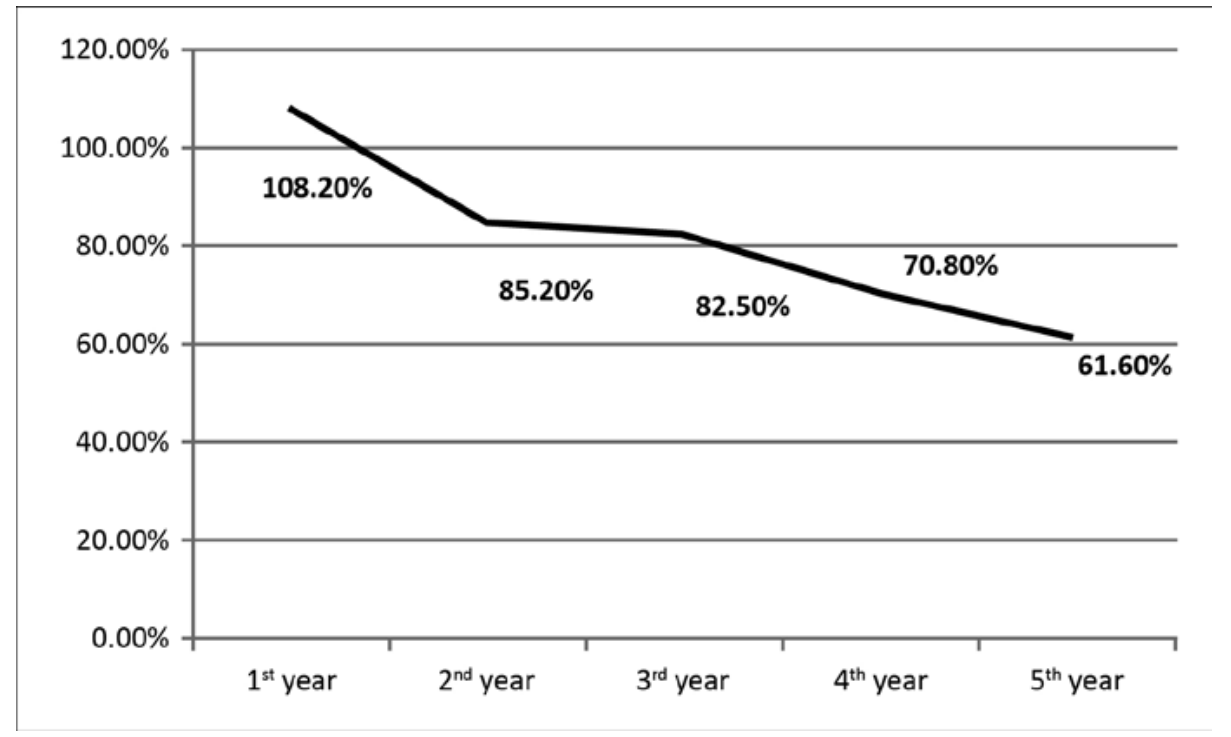

Figure 1. Loss ratio in a care model for older adults. Rio de Janeiro, 2014-2018.

As the program was implemented in July 2014, the first year was taken as July 2014 to June 2015; the second year from July 2015 to June 2016 , and so on.

Source: the author.

There is a constant decline in the loss ratio, which suggests that the actions proposed by the model yield highly positive results. It is expected that the loss ratio of an older population will be greater than that of younger people due to the greater demand for exams, consultations, treatment and hospitalizations. But the opposite occurred here, and the results were excellent.

\section{CONCLUSION}

Transforming the logic of health care in Brazil is both a major challenge and a necessity. It becomes even more relevant when it comes to health care for people in situations of greater vulnerability, such as older adults.

This model is structured based on a treatment system that favors integrated care and prevention through the continuous monitoring of health conditions and the coordination of care at all levels. In this way, it is possible to stabilize chronic diseases and avoid overburdening the system. The training and knowledge of healthcare professionals involved in the model must be continually kept up to date, to ensure they are as qualified as possible.

This type of change and innovation needs to be built into the daily reality of health services, into the training of health professionals, into the way the health system is managed and organized for care, and into its financing. It is impossible to talk about reorganizing the provision of services without considering remuneration models, as one determines the other. This debate must be tackled in order to move towards a higher quality of health care, and so that adequate remuneration can be provided.

It is possible to grow old with health and quality of life, as long as all those acting in the sector take responsibility and allow themselves to innovate. It is worth remembering that, often, innovating means salvaging the simpler care and values that have been lost within our health system. It is necessary to start constructing this new form of caring for older adults as soon as possible. 


\section{REFERENCES}

1. Veras RP, Estevam AA. Modelo de atenção à saúde do idoso: a ênfase sobre o primeiro nível de atenção. In: Lozer AC, Leles FAG, Coelho KSC, organizadores. Conhecimento técnico-científico para qualificação da saúde suplementar. Brasília, DF: OPAS; 2015. p. 73-84.

2. Szwarcwald CL, Damacena GN, de Souza Júnior PRB, Almeida WS, Malta DC. Percepção da população brasileira sobre a assistência prestada pelo médico. Ciênc Saúde Colet. 2016;21(2):339-50.

3. Veras RP, Oliveira MR. Linha de cuidado para o idoso: detalhando o modelo. Rev Bras Geriatr Gerontol. 2016;19(6):887-905.

4. Porter ME, Teisberg EO. Repensando a saúde: estratégias para melhorar a qualidade e reduzir os custos. Porto Alegre: Artmed; 2009.

5. de Moraes EM, de Moraes Fl. Avaliação multidimensional do idoso. Belo Horizonte: Folium; 2014.

6. Silva AMM, Mambrini JVM, Peixoto SV, Malta DC, Lima-Costa MF. Uso de serviços de saúde por idosos brasileiros com e sem limitação funcional. Rev Saúde Pública. 2017;51(supl.):1-10.

7. Carvalho VKS, Marques CP, Silva EN. A contribuição do Programa Mais Médicos: análise a partir das recomendações da OMS para provimento de médicos. Ciênc Saúde Colet. 2016;21(9):2773-84.

8. Veras RP, Oliveira M. Envelhecer no Brasil: a construção de um modelo de cuidado. Ciênc Saúde Colet. 2018;23(6):1929-36.

9. Veras RP, Caldas CP, Cordeiro HA. Modelos de atenção à saúde do idoso: pensando o sentido da prevenção. Physis. 2013;23(4):1189-1213.

10. Veras RP. Caring Senior: um modelo brasileiro de saúde com ênfase nas instâncias leves de cuidado. Rev Bras Geriatr Gerontol. 2018;21(3):1-7.

11. Veras RP, Gomes JAC, Macedo ST. A coordenação de cuidados amplia a qualidade assistencial e reduz custos. Rev Bras Geriatr Gerontol. 2019;22(2):e1900073 [12 p.].

12. Saenger ALF, Caldas CP, Motta LB. Adaptação transcultural para o Brasil do instrumento PRISMA-7: avaliação das equivalências conceitual, de item e semântica. Cad Saúde Pública. 2016;32(9):e00072015 [17 p.]

13. Turner G, Clegg A. Best practice guidelines for the management of frailty: a British Geriatrics Society, Age UK and Royal College of General Practitioners, report. Age Ageing. 2014;43:744-7.
14. Veras RP. Guia dos Instrumentos de Avaliação Geriátrica [Internet]. Rio de Janeiro: UnATI/ UERJ; 2019 [acesso em 10 abr. 2020]. Disponível em: http://www.unatiuerj.com.br/Guia $\% 20 \operatorname{dos} \% 20$ instrumentos $\% 20$ Avaliacao $\% 20$ Geriatrica.pdf

15. Veras R. Bem Cuidado: um modelo integrado com ênfase nas instâncias leves de cuidado. Rio de Janeiro: ANS; 2018.

16. Veras PR, Gomes JAC, Macedo ST. A coordenação de cuidados amplia a qualidade assistencial e reduz custos. Rev Bras Geriatr Gerontol. 2019;22(2):e1900073 [12 p.].

17. Veras RP, Caldas CP, da Motta LB, de Lima KC, Siqueira RC, Rodrigues RTSV, et al. Integração e continuidade do cuidado em modelos de rede de atenção à saúde para idosos frágeis. Rev Saúde Pública. 2014;48(2):357-65.

18. Oliveira MR, Veras RP, Cordeiro HA. Supplementary Health and aging after 19 years of regulation: where are we now? Rev Bras Geriatr Gerontol. 2017;20(5):624-33.

19. Costa ALFA, dos Santos VR. Da visão à cidadania: tipos de tabelas de avaliação funcional da leitura na educação especial. Rev Bras Oftalmol.2018;77(5):296-302.

20. Lourenço RA, Veras RP. Mini-Exame do Estado Mental: características psicométricas em idosos ambulatoriais. Rev Saúde Pública. 2006;40:712-9.

21. Machado RSP, Coelho MASC, Veras RP. Validity of the Portuguese version of the mini nutritional assessment in Brazilian elderly. BMC Geriatrics. 2015;15:1-10.

22. Nunes BP, Soares UM, Wachs LS, Volz PM, Saes MO, Duro MSS, et al. Hospitalização em idosos: associação com multimorbidade, atenção básica e plano de saúde. Rev Saúde Pública. 2017;51:1-10.

23. Caldas CP, Veras RP, da Motta LB, Guerra ACLC, Trocado CVM. Atendimento de emergência e suas interfaces: o cuidado de curta duração a idosos. J Bras Econ Saúde. 2015;7(1):62-9.

24. Oliveira MR, Veras RP, Cordeiro HA. O modelo de remuneração definindo a forma de cuidar. J Bras Econ Saúde. 2018;10(2):198-202.

25. Tanaka OU, Oliveira VE. Reforma(s) e estruturação do Sistema de Saúde Britânico: lições para o SUS. Saúde Soc. 2007;16(1):7-17.

26. Veras R. The Current Challenges of Health Care for the Elderly. J Gerontol Geriatr Res. 2015;4:1-1. 